\title{
ANALISIS RISIKO PRODUKSI USAHATERNAK SAPI PERAH PADA KELOMPOK TANI TERNAK DI KECAMATAN GETASAN SEMARANG
}

\author{
RISK PRODUCTION ANALYSIS OF DAIRY CATTLE LIVESTOCK BUSINESS AT \\ LIVESTOCK FARMER GROUPS IN GETASAN DISCTRICT SEMARANG
}

\author{
Berlian Syahrial Firdaus Al Farizqie, Wiludjeng Roessali, Suryani Nurfadillah \\ Agribisnis, Fakultas Peternakan dan Pertanian, Universitas Diponegoro, Semarang \\ Email : berliansfa@gmail.com \\ Diterima: 24 Nopember 2020, Direvisi: 30 Nopember 2020, Disetujui: 11 Desember 2020
}

\begin{abstract}
ABSTRAK
Pertumbuhan konsumsi susu sapi di Indonesia sebesar 5,09\% masih lebih tinggi dibandingkan dengan produksinya yaitu sebesar 3,17\%. Rendahnya produksi disebabkan karena produksi susu yang belum optimal dengan rata-rata sebesar 8,82 liter/ekor/hari, selain itu sering terjadi fluktuasi produksi. Fluktuasi tersebut menandai adanya risiko produksi menjadikan masalah baru untuk pengembangan sapi perah. Risiko pada usaha sapi perah menjadi penting untuk dikaji guna meningkatkan produktivitas dan pengembangan usaha sapi perah. Penelitian ini bertujuan untuk menganalisis besarnya tingkat risiko produksi dan sumber-sumber risiko produksi yang menjadi prioritas untuk ditangani serta strategi mitigasi yang tepat untuk menanganinya. Penelitian ini dilaksanakan pada bulan Maret 2020 di Kecamatan Getasan karena merupakan salah satu sentra sapi perah di Kabupaten Semarang. Penentuan lokasi KTT ditentukan secara purposive diambil KTT Rias di Desa Kopeng dengan pertimbangan memiliki lokasi yang cocok untuk budidaya sapi perah dan merupakan kelompok dengan jumlah ternak terbanyak di Desa Kopeng. Penentuan sampel menggunakan metode sensus dengan responden sebanyak 34 orang. Data primer diperoleh melalui wawancara peternak berdasarkan kuesioner dan observasi langsung. Data sekunder diperoleh melalui studi catatan yang ada di KTT Rias maupun literatur yang relevan. Analisis data menggunakan metode perhitungan kuantitatif dengan nilai Koefisien Variasi (KV) dan metode House of Risk (HOR). Hasil penelitian menunjukkan bahwa tingkat risiko produksi tergolong sangat tinggi dan mengalami fluktuasi ekstrim dengan nilai KV sebesar 22,39\%. Berdasarkan HOR fase 1 terdapat 9 sumber risiko penyebab utama terjadinya risiko yang menjadi prioritas untuk ditangani. Hasil HOR fase 2 didapatkan 3 strategi mitigasi yang menjadi prioritas untuk diterapkan guna menangani 9 sumber risiko tersebut.
\end{abstract}

Kata kunci: fluktuasi produksi, house of risk, koefisien variasi, risiko produksi

\section{ABSTRACT}

The growth of milk consumption in Indonesia amounted to 5.09\% is still higher compared with production with $3,17 \%$. The low production is caused by not optimal in milk production with an average of 8,82 litres/head/day, in addition there are fluctuations in production. These fluctuations mark the presence of production risk, make a new issue for the dairy cows development. The production risk becomes important to be studied in order to improve the productivity and development of dairy cattle business. The purpose of this study is to analyze the level of risk and the risk agents as well as a mitigation strategy to handle it. This research was conducted in the month of March 2020 in the Getasan District because it is one of the dairy centers in the Semarang Regency. The determination of the location of the Dairy Cattle Farmers 
Association (DCFA) is determined purposively taken the Rias DCFA in the Kopeng Village with consideration to have a suitable location for the cultivation of dairy cows and is the group with the number of cattle is highest in the Kopeng Village. The determination of the sample using the census method by the respondents as many as 34 people. The primary data obtained through interviews farmers based on questionnaires and direct observation. The secondary data obtained through the study note that there is at the Rias DCFA and relevant literature. Data analysis using quantitative calculation value of the Coefficient of Variation (KV) and House of Risk (HOR) method. The results showed that the level of production risk as very high and experienced the extreme fluctuations with the $K V$ value of 22.39\%. Based on the HOR phase 1 there are 9 risk agent the main cause of the risk events that become priority to be addressed. The results of the HOR phase 2 achieved 3 mitigation strategy priority to be applied to handle 9 of these risk agents.

Keyword : coefficient of variation, fluctuations in production, house of risk, production risk

\section{PENDAHULUAN}

Konsumsi susu masyarakat Indonesia mengalami peningkatan, seiring dengan bertambahnya populasi, meningkatnya tingkat ekonomi dan kesadaran masyarakat akan hidup sehat (Mukson et al., 2010). Kementerian Pertanian (2018) memprediksi pertumbuhan konsumsi dari tahun 2016 hingga tahun 2021 yaitu sebesar 5,09\%, sedangkan peningkatan pertumbuh-an produksinya hanya sebesar 3,17\% dari tahun 2016 hingga tahun 2021. Defisit rata-rata antara produksi dan konsumsi susu nasional cukup tinggi yaitu sebesar 92.302,3 ton/tahun. Kesenjangan antara produksi dan konsumsi tersebut menyebabkan impor susu terus meningkat.

Tingkat produksi susu nasional yang rendah disebabkan karena skala kepemilikan ternak yang relatif kecil pada peternak lokal, praktek pemberian pakan yang buruk dengan kualitas dan kuantitas pakan yang rendah, rendahnya tingkat kebersihan kandang serta penanganan pasca panen dan pemasaran produk yang terbatas (Mukson et al, 2017). Kondisi peternakan sapi perah di Indonesia ditandai dengan kepemilikan ternak yang kecil dengan rata-rata kepemilikan kurang dari 2 ekor ternak (Roessali et al, 2011), dan penggunaan teknologi yang masih sederhana (Setiadi et al, 2020), sehingga menyebabkan kurang efisien dalam produksi.

Skala usaha yang relatif kecil menggambarkan kondisi bahwa peternak dihadapkan pada keterbatasan faktor produksi, manajemen dan teknologi pemeliharaanya (Astuti et al., 2010). Salah satu strategi untuk mengatasinya yaitu dengan membentuk kelompok ternak dengan harapan dapat meningkatkan skala usaha, efisiensi produksi dan dapat mengatasi keterbatasan-keterbatasan sumberdaya sehingga produksi dapat meningkat. Namun, kenyataannya masih banyak kelompok tani ternak yang produksinya berfluktuasi dan belum mampu mencapai efisiensi produksi (Astuti et al., 2010; Aisyah, 2012; Utami et al., 2020).

Kabupaten Semarang merupakan salah satu sentra produksi susu sapi perah di Jawa Tengah, namun selama periode 2013 - 2017 produksi susu sapi perah mengalami fluktuasi. Produksi susu yang dihasilkan disumbang oleh 121 kelompok tani ternak yang tersebar di Kabupaten Semarang (Dinas Pertanian Perikanan dan Pangan Kabupaten Semarang, 2020). Salah satu daerah di Kabupaten Semarang yang menjadi basis untuk pengembangan sapi perah yaitu Kecamatan Getasan (Mukson et al., 2017) 
Salah satu dari 59 kelompok tersebut yaitu Kelompok Tani Ternak (KTT) Rias yang terletak di Desa Kopeng, Kecamatan Getasan. KTT Rias merupakan salah satu KTT yang memiliki jumlah ternak sapi perah terbanyak di Kecamatan Getasan. Lokasinya yang merupakan dataran tertinggi di wilayah Getasan menjadikan daerah tersebut sangat baik untuk mengembangkan usaha ternak termasuk sapi dan kambing (Mukson et al, 2010). Kondisi iklim yang sesuai ternyata belum mampu membuat KTT tersebut berprodu-ksi optimal dan stabil, masih terdapat fluktuasi produksi setiap periodenya. Produktivitas susu yang tergolong rendah untuk ukuran sapi $\mathrm{FH}$ dengan rata-rata sebesar 8 liter per ekor per hari (Mukson et al., 2017), selain itu adanya risiko produksi dengan ditandai fluktuasi produksi menjadikan suatu masalah baru untuk pengembangan sapi perah. Kesediaan peternak untuk menghadapi dan mengambil risiko mempengaruhi usaha untuk meningkatkan skala bisnis sapi perah (Eddy et al, 2012).

Berdasarkan uraian diatas untuk meningkatkan produktivitas serta pengembangan usaha, peternak harus berani mengambil risiko dalam usaha sapi perah. Risiko dalam sapi perah perlu dikaji untuk membantu peternak dalam menetapkan strategi guna menghadapi risiko yang ada agar usaha sapi perah dapat berkembang. Oleh karena itu, penelitian ini bertujuan untuk menganalisis besarnya tingkat risiko produksi di KTT Rias, sumber risiko utama yang menjadi prioritas untuk ditangani dan strategi mitigasi prioritas untuk diterapkan.

\section{BAHAN DAN METODE PENELITIAN}

Penelitian ini dilakukan di di Desa Kopeng, Kecamatan Getasan, Kabupaten Semarang pada bulan Maret - Mei 2020. Pemilihan lokasi dilakukan secara sengaja (purposive) dengan pertimbangan bahwa
Kecamatan Getasan merupakan sentra sapi perah di Kabupaten Semarang. Lokasi KTT yang diambil yaitu KTT Rias di Desa Kopeng dengan berdasarkan pertimbangan bahwa KTT Rias merupakan kelompok dengan populasi ternak terbanyak di Desa Kopeng dengan jumlah 180 ekor sapi perah.

Materi dalam penelitian ini berupa bahan dan alat. Bahan yang digunakan dalam penelitian ini yaitu kuesioner yang telah disediakan, data produksi susu, data kondisi kelompok ternak dan data kondisi geografis. Alat yang digunakan adalah alat tulis dan telepon genggam dan kamera. Jenis data yang digunakan yaitu data primer dan data sekunder. Data diambil secara langsung melalui wawancara kepada responden. Semua anggota KTT Rias sebanyak 34 orang digunakan sebagai responden dalam penelitian.

Metode yang digunakan untuk menganalisis tingkat risiko menggunakan metode perhitungan kuantitatif menggunakan nilai koefisien variasi (KV) dengan langkah-langkah sebagai berikut :

Menghitung expected return $\left(\mathrm{R}_{\mathrm{ij}}\right)$ menurut Lesmana (2013) dengan rumus sebagai berikut:

$\mathrm{R}_{\mathrm{ij}}=\sum_{\mathrm{i}=1}^{\mathrm{n}} \mathrm{p}_{\mathrm{i}} \times \mathrm{R}_{\mathrm{i}}$

Keterangan :

$\mathrm{R}_{\mathrm{ij}} \quad=$ expected return

$\mathrm{p}_{\mathrm{i}} \quad=$ peluang

$\mathrm{R}_{\mathrm{i}} \quad=$ produksi aktual

Besarnya risiko produksi dapat diketahui dengan menghitung simpangan baku (standar deviasi). Standar deviasi dapat dihitung dengan rumus sebagai berikut (Rarasati et al, 2015):

$\mathrm{S}=\sqrt{\sum_{i=1}^{n} p_{i}\left(R_{i}-R_{i j}\right)^{2}}$

Keterangan:

$\mathrm{S} \quad=$ simpangan baku (standar deviasi)

Tingkat risiko produksi dapat diketahui dengan menghitung nilai $\mathrm{KV}$ (koefisien variasi). KV dihitung dengan rumus: 
$\mathrm{KV}=\frac{\mathrm{s}}{\mathrm{Rij}}$

Keterangan :

$\mathrm{KV}=$ koefisien variasi

Metode yang digunakan untuk menganalisis sumber risiko yang menjadi prioritas untuk ditangani dan strategi mitigasinya menggunakan metode House of Risk (HOR). HoR digunakan untuk manajemen risiko dengan melalui identifikasi risiko dan menyusun strategi mitigasi risiko yang efektif sehingga dapat mengurangi kejadian risiko yang ada (Wastra et al., 2018). HOR memiliki dua fase, fase satu untuk menentukan sumber risiko yang menjadi prioritas untuk ditangani sedangkan fase dua untuk menentukan strategi mitigasi yang menjadi prioritas untuk menangani sumber risiko tersebut (Punjawan dan Geraldin, 2009).

Fase satu dimulai dengan mengidentifikasi kejadian risiko dan diberikan nilai keparahan (severity) dengan skala $1-10$, dengan nilai 10 menunjukkan sangat parah dampak yang ditimbulkan. Identifikasi sumber risiko penyebab kejadian risiko yang telah diidentifikasi sebelumnya dan diberikan penilaian frekuensi kemungkinan terjadinya (occurance) dengan skala $1-10$. Tentunkan korelasi antara sumber risiko dengan kejadian risiko dengan nilai korelasi $(0,1,3,9)$, dimana nilai 9 artinya korelasi tinggi dan nilai 0 tidak ada korelasi. Pilih sumber risiko yang menjadi prioritas untuk ditangani berdasarkan nilai agregat potensial risiko (ARP). Nilai ARP dihitung menggunakan rumus berikut:

$\mathrm{ARP}=\mathrm{O} \sum \mathrm{S} . \mathrm{R}$

Keterangan :

$\mathrm{ARP}=$ agregat potensial risiko

$\mathrm{O}=$ nilai occurance sumber risiko

$\mathrm{S} \quad=$ nilai severity kejadian risiko

$\mathrm{R}=$ nilai korelasi

Fase dua dimulai dengan memilih sumber risiko yang memiliki nilai ARP tertinggi menggunakan analisis pareto dan diambil 75\% ARP tertinggi. Tahap selanjutnya yaitu mengidentifikasi strategi mitigasi yang relevan dengan sumber risiko yang dipilih dan menentukan korelasi antara strategi mitigasi dan sumber risiko dengan nilai $(0,1,3,9)$. Menghitung tingkat efektivitas strategi mitigasi yang dipilih untuk menangani sumber risiko dengan rumus sebagai beriku:

$\mathrm{TEk}=\sum \mathrm{ARP} \times \mathrm{Ejk}$

Keterangan:

TEk = tingkat efektivitas

$\mathrm{Ek}=$ korelasi antara strategi mitigasi dan sumber risiko

Berikan nilai tingkat kesulitan penerapan strategi mitigasi dengan skala 3 untuk mudah, 4 untuk sedang dan 5 untuk sulit. Tingkat kesulitan didasarkan pada ketersediaan sumber finansial dan sumber daya lainnya yang dimiliki peternak. Pemilihan strategi mitigasi yang menjadi prioritas didasarkan pada nilai rasio total efektivitas dengan tingkat kesulitan (ETDk). Rasio ETDk dapat dihitung dengan rumus berikut:

$\mathrm{ETDk}=\frac{\mathrm{TEk}}{\mathrm{Dk}}$

Keterangan :

ETDk = rasio efektivitas mitigasi

TEk =tingkat efektivitas strategi mitigasi

Dk =tingkat kesulitan penerapan strategi mitigasi

\section{HASIL DAN PEMBAHASAN Risiko Produksi}

Risiko produksi ditandai dengan adanya fluktuasi produksi yang dihasilkan oleh suatu usaha. Kahan (2006) berpendapat bahwa risiko produksi terjadi karena adanya fluktuasi kondisi (kuantitas, kualitas maupun kontinuitas) input sehingga menyebabkan terjadinya fluktuasi produksi. 


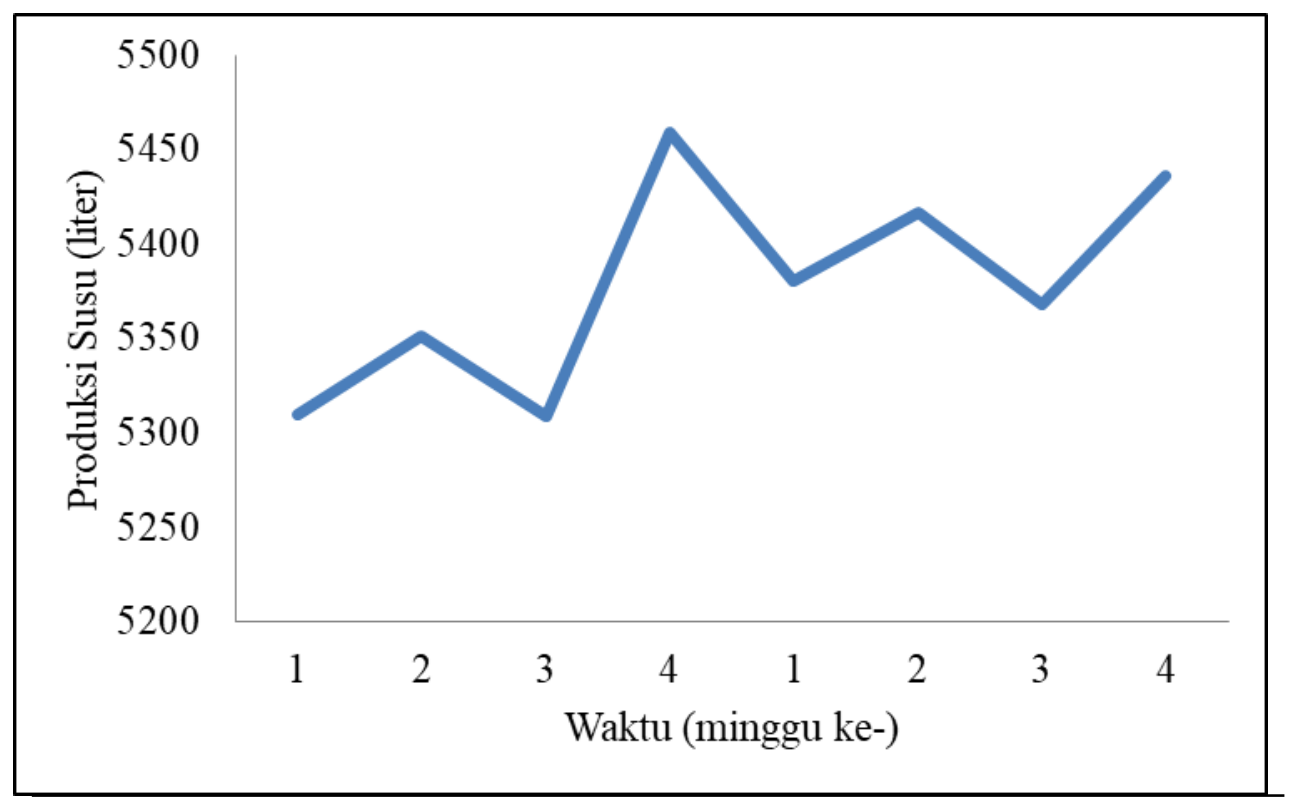

\section{Gambar 1.}

Produksi Susu Bulan April - Mei 2020

KTT Rias mengalami fluktuasi produksi selama periode produksi bulan April hingga Mei 2020 seperti terlihat pada Gambar 1. Produksi tertinggi selama pengamatan terjadi pada minggu ke 4 di bulan April sebesar 5.459 liter dan terendah pada bulan April minggu ke 1 . Fluktuasi produksi terjadi setiap minggunya, terlihat dari pertumbuhan produksi susu yang bernilai positif dan negatif dengan penurunan tertinggi sebesar $1,45 \%$ dan pertumbuhan tertinggi sebesar 2,83\%. Fluktuasi produksi tersebut menandakan adanya risiko produksi pada KTT Rias. Shinta dan Wiyono (2017) mengungkapkan peningkatan dan penurunan produksi yang disebabkan oleh faktor internal dan eksternal produksi merupakan indikator terjadinya risiko produksi pada usaha tersebut.

Tabel 1.

Perhitungan Risiko Produksi

\begin{tabular}{lcr}
\hline \multicolumn{1}{c}{ Uraian } & Satuan & \multicolumn{1}{c}{ Nilai } \\
\hline Produksi Total & Liter/2 bulan/95 ekor & $43.030,00$ \\
Rata-rata Produksi & Liter/minggu/95 ekor & 5378,75 \\
Standar Deviasi & Liter & 963,31 \\
Koefisien Variasi & & 0,22 \\
KV & $\%$ & $22,39 \%$ \\
\hline
\end{tabular}

Sumber : Data Primer 2020

Tabel 2. menunjukkan banyaknya produksi pada kelompok tani ternak Rias dalam dua bulan yaitu sebanyak 43.030 liter. Rata-rata produksi perminggunya sebesar 5.378,75 liter dari 95 ekor sapi laktasi atau sebesar 8,09 liter/ekor/hari. Rata-rata produksi yang dihasilkan sama dengan hasil yang dilaporkan Mukson et 
al (2017) pada lokasi yang sama, dimana rata-rata produksinya sebesar 5-8 liter/ ekor/hari. Eddy et al (2012) melaporkan bahwa rata-rata produksi susu pada Kecamatan Getasan di Desa Batur, Tajuk dan Jetak sedikit lebih tinggi yaitu sebesar 8,82 liter/ekor/hari. Thau (2004) menyatakan bahwa beberapa faktor yang mempengaruhi produksi yaitu tingkat pendidikan, lamanya pengalaman berternak, ketersediaan modal dan kredit, penyuluh dan pelatihan untuk peternak.

Standar deviasi diperoleh nilai sebesar 963,31, yang artinya bahwa besarnya risiko yang terjadi setiap minggunya sebesar 936,31 liter. Standar deviasi ini masih lebih rendah dari pada yang dilaporkan oleh Tasripin et al (2020), penelitian berlokasi di Bandung Selatan yang melaporkan bahwa standar deviasi yang diperoleh sebesar 1.965 liter. Fadil et al (2016) melaporkan dari penelitiannya di Baturraden bahwa standar deviasi 954,59 liter. Menurut Offayana et al. (2016) nilai standar deviasi menunjukkan besarnya tingkat risiko yang terjadi dari hasil produksi suatu usaha. Lesmana (2013) menambahkan semakin tinggi nilai standar deviasi maka semakin tinggi pula tingkat risiko yang dihadapi.
Pengukuran besarnya tingkat risiko produksi dapat ditentukan dengan cara menghitung nilai KV. Nilai KV yang didapatkan sebesar 22,39\%, artinya dari semua produksi yang dihasilkan terdapat fluktuasi produksi atau kemungkinan terjadinya risiko sebesar 22,39\%. Nilai KV dari produksi susu sebesar 22,39\% mengindikasikan bahwa risiko produksi pada KTT Rias tergolong sangat tinggi. Hal ini sesuai dengan pendapat dari Kountur (2018) bahwa risiko dengan tingkat kemungkinan terjadinya lebih besar dari 22,39\% termasuk kategori tingkat risiko yang sangat tinggi. Kementerian Perdagangan Republik Indonesia (2015) menambahkan bahwa nilai KV yang lebih dari $9 \%$ menunjukkan bahwa komoditas susu dari KTT Rias belum stabil atau mengalami fluktuasi yang ekstrim.

\section{House Of Risk Fase 1}

Tingkat risiko yang dihadapi KTT Rias tergolong sangat tinggi, sehingga perlu dilakukan penanganan yang tepat. Metode House of Risk dapat digunakan untuk menentukan strategi mitigasi yang tepat, untuk menentukan strategi perlu diidentifikasi terlebih dahulu kejadian risiko serta sumber risiko penyebabnya. 


\section{Tabel 2.}

Daftar Kejadian Risiko Produksi (Risk Event)

\begin{tabular}{|c|c|c|c|}
\hline Proses Utama & Kejadian Risiko (Risk Event) & Kode $(\mathrm{Ej})$ & Severity \\
\hline \multirow[t]{3}{*}{ Plan } & Tidak adanya perhitungan forecasting & E1 & 1,55 \\
\hline & Kurangnya biaya untuk produksi & E2 & 3,95 \\
\hline & Target produksi tidak tercapai & E3 & 4,80 \\
\hline \multirow[t]{8}{*}{ Source } & Kesalahan pembelian peralatan kandang & E4 & 1,55 \\
\hline & Kesalahan pembelian pakan konsentrat & E5 & 2,45 \\
\hline & $\begin{array}{l}\text { Keterlambatan pengiriman pakan } \\
\text { konsentrat }\end{array}$ & E6 & 1,45 \\
\hline & Kesalahan pembelian obat & E7 & 4,05 \\
\hline & Kesalahan pemilihan bibit sapi & E8 & 3,25 \\
\hline & Kekurangan pakan hijauan & E9 & 4,80 \\
\hline & Kegagalan IB/SC tinggi & E10 & 3,90 \\
\hline & Kemunduran rencana waktu produksi & E11 & 4,25 \\
\hline \multirow[t]{12}{*}{ Make } & Kesalahan dalam pemberian pakan & E12 & 3,75 \\
\hline & Kematian induk dan anakan & E13 & 2,70 \\
\hline & Infeksi pada bagian tubuh sapi & E14 & 5,70 \\
\hline & Sapi mengalami hipocalsemia & E15 & 4,05 \\
\hline & Sapi mengalami mastitis & E16 & 3,70 \\
\hline & Terdapat kotoran pada susu & E17 & 4,25 \\
\hline & Susu tercecer saat pemerahan & E18 & 4,10 \\
\hline & Susu tercemar aroma sapi & E19 & 4,20 \\
\hline & Sapi kurang tenang saat pemerahaan & E20 & 4,30 \\
\hline & Sapi mengalami demam & $\mathrm{E} 21$ & 3,40 \\
\hline & Penurunan produksi susu & $\mathrm{E} 22$ & 3,65 \\
\hline & Susu tumpah saat penyaringan & E23 & 3,30 \\
\hline \multirow[t]{3}{*}{ Deliver } & Tumpah saat proses pengemasan & E24 & 1,80 \\
\hline & Kerusakan susu saat penyimpanan & $\mathrm{E} 25$ & 1,45 \\
\hline & Rendahnya kualitas susu & E26 & 2,45 \\
\hline \multirow[t]{3}{*}{ Return } & Susu ditolak oleh koperasi & E27 & 1,00 \\
\hline & Susu tidak terjual habis & E28 & 1,00 \\
\hline & Berkurangnya pendapatan peternak & E29 & 4,55 \\
\hline
\end{tabular}

Keterangan : IB = Inseminasi Buatan

$\mathrm{SC}=$ Service per Conception

Penentuan sumber risiko yang menjadi prioritas dapat menggunakan metode House of Risk fase 1. Menurut Punjawan dan Geraldin (2009) langkah pertama untuk menentukan prioritas sumber risiko adalah dengan mengidentifikasi dan mengukur kejadian risiko (risk event) serta sumber risiko (risk agent).
Berdasarkan Tabel 3. didapatkan 29 kejadian risiko dimana masing masing terdapat 3 kejadian risiko perencanaan, 8 kejadian risiko pada pengadaan, 12 kejadian risiko pada produksi, 3 kejadian risiko pada deliver dan 3 kejadian risiko pada return. Penilaian kejadian risiko diberikan berdasarkan tingkat keparahannya (severity) atau dampak 
kerugian yang dihasilkan. Dampak yang dihasilkan semakin besar, maka semakin besar pula nilai yang diberikan. Menurut Wastra et al. (2018) nilai yang diberikan didasarkan pada keparahan atau efek dari terjadinya risiko terhadap hasil yang didapatkan, semakin besar kerugian yang dihasilkan semakin besar pula nilai yang diberikan.
Tahap selanjutnya untuk penanggulangan risiko yaitu mengidentifikasi sumber risiko atau agen risiko yang menjadi penyebab terjadinya kejadian risiko dan memberikan penilaian occurrence-nya (tingkat frekuansi kejadian).

Tabel 3.

Daftar Agen Risiko Produksi (Risk Agent)

\begin{tabular}{clc}
\hline \hline Kode & \multicolumn{1}{c}{ Agen (Sumber) Risiko } & $\begin{array}{c}\text { Tingkat Kejadian } \\
\text { (Occurrence) }\end{array}$ \\
\hline A1 & Peternak tidak melakukan forecasting & 9,25 \\
A2 & Referensi harga yang kurang akurat & 4,30 \\
A3 & Keterbatasan modal & 4,60 \\
A4 & Tingginya target produksi yang ditetapkan & 5,30 \\
A5 & Kekurangan supply input & 4,50 \\
A6 & Pengetahuan beternak rendah & 4,05 \\
A7 & Kondisi cuaca ekstrem/perubahan cuaca yang drastis & 9,20 \\
A8 & Pemberian konsentrat yang tidak sesuai (jumlah dan & 4,20 \\
& kualitas) & \\
A9 & Rendahnya kedisiplinan peternak & 4,85 \\
A10 & Kesalahan pemberian obat & 2,15 \\
A11 & Kesulitan melahirkan/distokia & 2,05 \\
A12 & Sanitasi kandang kurang bersih & 3,80 \\
A13 & Kebersihan sapi kurang & 8,90 \\
A14 & Peternak terburu-buru dalam hal pemeliharaan sapi & 6,20 \\
A15 & Kualitas induk kurang baik & 4,25 \\
A16 & Kerusakan peralatan kandang & 4,70 \\
A17 & Peternak kurang cermat dalam memperhatikan tanda- & 5,05 \\
& tanda birahi & \\
A18 & Pengetahuan tentang pakan rendah & 6,15 \\
A19 & Peternak tidak melakukan pemerahan dengan benar & 9,15 \\
A20 & Penanganan sapi sakit kurang baik & 2,25 \\
A21 & Peternak kurang hati-hati saat pengemasan & 2,80 \\
A22 & Tidak adanya alat pemeriksaan kualitas susu & 1,30 \\
A23 & Kerusakan pada alat penyimpanan & 1,25 \\
A24 & Rusaknya alat transportasi susu & 1,50 \\
A25 & Harga susu yang diterapkan koperasi rendah & 1,40 \\
\hline Sura & Data Prime2020 &
\end{tabular}

Sumber : Data Primer 2020

Berdasarkan Tabel 4. didapatkan 25 sumber risiko produksi dimana nilai dari occurrence didasarkan pada frekuensi terjadinya sumber risiko penyebab kejadian risiko yang terjadi. Tingkat occurance menunjukkan peluang masing- 
masing sumber risiko produksi mungkin terjadi (Punjawan dan Geraldine, 2009). Sama halnya dengan nilai severity, bersarnya nilai pada occurance diberikan atas dasar tingkat keterjadian atau keseringan dari agen risiko tersebut muncul dan menyebabkan terjadinya risiko produksi (Munawir dan Krismiyanto, 2016).

Pemetaan sumber risiko yang menjadi prioritas dilakukan dengan menggunakan diagram pareto (Gambar 1). Total 25 sumber risiko diambil $75 \%$ kumulatif agregat risiko potensial (ARP) dari sumber risiko. Nilai ARP (Agregat Risk Potential) diperoleh berdasarkan pada nilai severity, occurance dan korelasi antara sumber risiko dengan kejadian risiko (Wastra et al., 2018). Penentuan rangking prioritas sumber risiko menggunakan perhitungan pareto yang dapat digambarkan dalam diagram pareto (Shinta dan Wiyono, 2017).

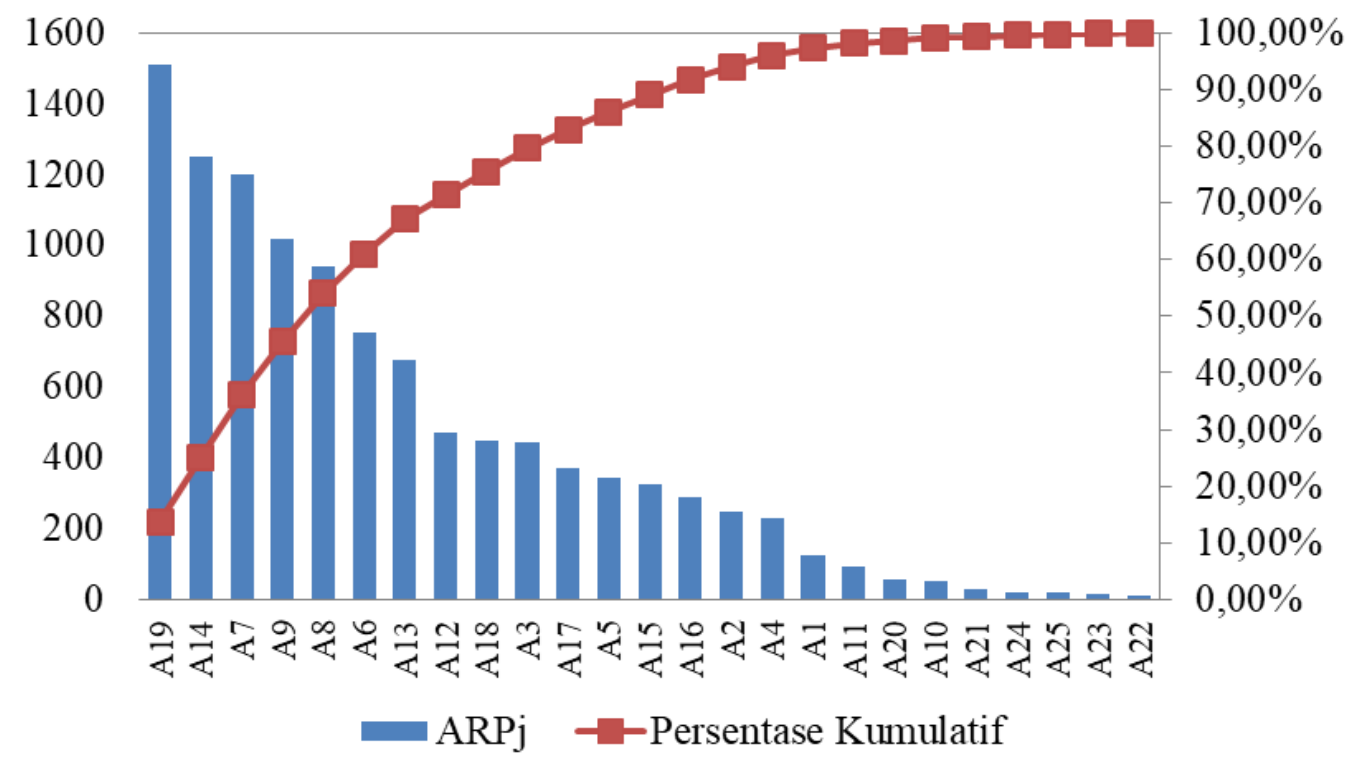

Gambar 2.

Diagram Pareto Agregat Risiko Potensial

Berdasarkan diagram pareto diatas didapatkan 9 sumber risiko yang menjadi prioritas untuk ditangani yaitu A19, A14, A7, A9, A8, A6, A13, A12, dan A18. Sembilan sumber risiko dipilih berdasarkan kontribusinya terhadap persentase ARP kumulatif sebanyak $75 \%$ pada diagram pareto (Punjawan dan Geraldin, 2009).

\section{House of Risk Fase 2}

Penanganan sumber risiko dilakukan menggunakan strategi mitigasi. Pemilihan strategi mitigasi yang menjadi prioritas untuk diterapkan berdasarkan kemudahan sumberdaya dan kondisi finansial dari peternak serta memiliki efektifitas yang tinggi dapat ditentukan melalui House of Risk fase 2. Langkah House of Risk fase 2 yaitu identifikasi strategi mitigasi dan menentukan tingkat kesulitan kemudian menghitung nilai efektifitas strategi mitigasi berdasarkan nilai tingkat kesulitannya dan korelasinya dengan sumber risiko. Tingkat kesulitan penerapan strategi mitigasi menggunakan nilai dengan skala 3 (tingkat kesulitan 
rendah), 4 (tingkat kesulitan sedang) dan 5 (tingkat kesulitan tinggi).

\section{Tabel 4.}

Strategi Mitigasi Matriks HOR Fase 2 (Preventive Actions)

\begin{tabular}{|c|c|c|c|c|}
\hline Kode & Strategi Mitigasi & Dk & $\begin{array}{c}\text { Tingkat } \\
\text { Efektivitas }\end{array}$ & Rangking \\
\hline S1 & Membuat SOP pemerahan yang benar & 3,2 & 4058,7 & 8 \\
\hline $\mathrm{S} 2$ & $\begin{array}{l}\text { Perbaikan manajemen pakan dan pembuatan } \\
\text { SOP pemberian pakan yang baik dan benar }\end{array}$ & 3,2 & 8086,1 & 3 \\
\hline S3 & Penambahan kipas angin pada kandang & 4,8 & 2254,6 & 12 \\
\hline S4 & Membuat gudang penyimpanan pakan & 3,0 & 8315,0 & 2 \\
\hline S5 & Pembelian alat pemerahan & 4,5 & 4696,6 & 6 \\
\hline S6 & $\begin{array}{l}\text { Menyediakan penyuluhan/pendidikan lebih } \\
\text { pada peternak }\end{array}$ & 3,2 & 8432,2 & 1 \\
\hline S7 & Membuat SOP kebersihan kandang & 4,5 & 2687,4 & 11 \\
\hline S8 & $\begin{array}{l}\text { Membuat standar operasional dan kelayakan } \\
\text { prosedur pemerahan }\end{array}$ & 4,3 & 6184,2 & 4 \\
\hline S9 & Penambahan tenaga kerja & 4,7 & 3093,6 & 10 \\
\hline S10 & $\begin{array}{l}\text { Menjalin komunikasi yang baik dengan } \\
\text { dinas perternakan setempat agar dapat } \\
\text { membantu mengatasi permasalahan } \\
\text { peternak }\end{array}$ & 3,0 & 4342,9 & 7 \\
\hline S11 & Mengembangkan usaha selain sapi perah & 3,5 & 4808,8 & 5 \\
\hline S12 & $\begin{array}{l}\text { Membuat pakan fermentasi untuk } \\
\text { persediaan }\end{array}$ & 3,7 & 4015,4 & 9 \\
\hline
\end{tabular}

Keterangan : Dk = Tingkat Kesulitan

Berdasarkan Tabel 5. didapatkan prioritas strategi mitigasi dengan nilai ETD tertinggi yaitu menyediakan penyuluhan/pendidikan bagi peternak sebesar 8432,2. Nilai ETD terendah yaitu pada strategi penambahan kipas angin sebesar 2254,6. Rendahnya strategi tersebut dikarenakan faktor biaya yang dibutuhkan untuk membeli kipas angin, selain itu faktor sumberdaya lain seperti listrik dan tenaga pemasang kipas angin tidak memadai.

Tindakan mitigasi yang diidentifikasi secara umum dapat bersifat strategis maupun taktis (Punjawan dan Geraldine, 2009). Strategi mitigasi yang dipilih mengacu pada pendapat Kahan (2008) berupa risk reducing-technologies yang berupa penambahan kipas angin untuk mengatasi cuaca ekstrim, penambahan alat pemerahan untuk meminimalisir kesalahan pemerahan. Production diversification yang meliputi pengembangan komoditas lain bersamaan dengan sapi perah, penerapannya yang dilakukan peternak yaitu budidaya sayuran hias dan menghasilkan penghasilan dari pekerjaan diluar usaha tani (off-farm).

Berdasarkan hasil ETD, dipilih 3 prioritas strategi mitigasi yang memiliki nilai ETD tertinggi untuk diterapkan di kelompok tani ternak Rias. Pertama, yaitu memberikan penyuluhan/pendidikan lebih kepada peternak. Pelaksanaannya berupa pemberian materi penyuluhan dengan menekankan tentang teknis pemerahan yang benar, tentang budidaya atau pemeliharaan sapi sesuai Good Dairy Farming Practise (GDFP) meliputi aspek pembibitan dan reproduksi, manajemen 
pakan dan air, pengelolaan kebersihan kandang dan peralatan, dan kesehatan ternak. Pemberian penyuluhan tentang pencegahan dan penanganan penyakit sapi yang baik dan benar. Program penyuluhan tersebut selain pemberian materi, tedapat pendampingan program pendampingan dari penyuluh untuk memantau langsung kondisi yang ada di kelompok. Bakhtiar dan Novanda (2018) menyatakan penyediaan penyuluh yang siap memberikan penyuluhan dan bantuan kepada peternak dapat menyokong dan meningkatkan produktivitas usahatani.

Strategi kedua, yaitu penambahan/ pembuatan gudang penyipanan pakan. Pelaksanaannya yaitu dengan kerjasama antar peternak untuk pembangunan gudang penyimpanan pakan. Pembuatan gudang penyimpanan pakan ini sekaligus untuk penyimpanan stok bahan pakan sehingga peternak dapat melakukan pemesanan bahan pakan dalam skala besar agar lebih efisien, selain itu dapat digunakan untuk penyimpanan dan pembuatan pakan silase, penyimpanan obat dan bahan tambahan untuk campuran pakan (vitamin dan mineral).

Ketiga, yaitu perbaikan manajemen pakan dan pembuatan SOP pemberian pakan yang baik dan benar. Deskripsi strategi ini yaitu memberikan pakan hijauan dan konsentrat sesuai dengan kebutuhan sapi berdasarkan bobot badannya. Waktu dan frekuensi pemberian pakan harus selalu tepat dan sama. Selalu menjaga kebersihan tempat pakan dan minum. Pemberian air minum dilakukan secara ad libitum atau dapat dilakukan bersamaan dengan pemberian pakan. Memperhatikan nutrisi dari pakan yang diberikan agar sesuai dengan kebutuhan sapi (penambahan kandungan kalsium).

\section{SIMPULAN}

Tingkat risiko produksi pada KTT Rias tergolong tinggi yang menandakan terjadinya fluktuasi produksi yang ekstim ditandai dengan nilai KV sebesar 22,39\%. Tingginya risiko produksi disebabkan oleh 9 sumber risiko yang memiliki potensi terbesar menyebabkan kerugian. Penanganan sumber risiko tersebut dapat dilakukan dengan 3 strategi mitigasi yang memiliki efektivitas tinggi serta kemudahan dalam penerapan maupun pelaksanaannya. Sebaiknya peternak menerapkan strategi yang efektif serta memiliki kemudahan dalam penerapan sesuai dengan finansial dan sumberdaya lain yang dimiliki peternak. 


\section{DAFTAR PUSTAKA}

Aisyah, S. 2012. Analisis efisiensi penggunaan faktor-faktor produksi pada usaha ternak sapi perah rakyat di Kecamatan Getasan Kabupaten Semarang. Economics Development Analysis Journal. 1(1) : 35 41.http://journal.unnes.ac.id/sju/ind ex.php/edaj

Astuti, M., R. Widiati dan Y. Y. Suranindyah. 2010. Efisien produksi usaha sapi perah rakyat (studi kasus pada peternakan anggota Koperasi Usaha Peternakan dan Pemerahan Sapi Perah Kaliurang, Sleman, Yogyakarta). Buletin Peternakan. 34 (1) : $64-69$.

Bakhtiar, A. and R. R. Novanda. 2018. The relationship between the adoption of innovation and the communication channel of Madura Cattle farmers. Journal of Socioeconomics and Development, 1(2), 72-78. https://doi.org/ 10.31328/jsed.v1i2.604

Dinas Pertanian Perikanan dan Pangan Kabupaten Semarang. 2020. Data Kelompok Tani Kabupaten Semarang. Dinas Pertanian Perikanan dan Pangan Kabupaten Semarang, Semarang. (Tidak Dipublikasikan).

Eddy, B. T., W. Roessali and S. Marzuki. 2012. Dairy cattle farmers' behaviour and factors affecting the effort to enhance the economic of scale at Getasan District, Semarang Regency. J. Indonesian Tropical Animal Agriculture. 37 (1) : 34 40.

Fadil, D. D., A. Anang dan H. Indrijani. 2016. Uji produksi susu sapi friesian holstein keturunan pejantan impor di BBPTU-HPT Baturraden. Student e-Journal. 4(4)
$: 1$ - 13. https://jurnal.unpad.ac.id/ ejournal/article/view/8063

Kahan, D. 2008. Managing Risk in Farming. FAO, Rome, Italy.

Kementerian Perdagangan Republik Indonesia. 2015. Rencana Strategis Kementerian Perdagangan Tahun 2015 - 2019. Kementerian Perdagangan Republik Indonesia. Jakarta.

Kementerian Pertanian, 2018. Outlook Susu 2018. Pusdatin Sekretariat Jendral Kementan, Jakarta.

Kountur, R. 2018. Manajemen Risiko. Abdi Tandur, Jakarta.

Lesmana, T. A. 2013. Analisis faktorfaktor produksi yang mempengaruhi risiko produksi dan analisis risiko harga tomat di Desa Gekbrong Kabupaten Cianjur. Program Sarjana, Institut Pertanian Bogor, Bogor. (Skripsi Sarjana Ekonomi).

Mukson, Isbandi, K. Budiraharjo, M. Handayani and N. W. Listiani, 2010. Profitability level and the role of family factors resources for developing dairy cattle farming in Getasan-Semarang District. Prosiding Seminar Nasional Ruminansia 2010. Fakultas Peternakan UNDIP, Semarang, October 6, 2010. 127 - 130.

Mukson, M., H. Setiyawan, M. Handayani and A. Setiadi. 2017. Analysis of local resource-based dairy cattle development in Central Java. J. Indonesian Tropical Animal Agriculture. 42 (1) : 48 - 56.

Mukson, T. Ekowati, M. Handayani and S. Gayatri. 2010. The potency of dairy cattle agribusiness development in Semarang Regency, Central Java. J. Indonesian Tropical Animal Agriculture. 35 (3) : $179-184$. 
Munawir, H. dan Krismiyanto. 2016. Analisis risiko dan strategi mitigasi risiko supply cain susu sapi (studi kasus di Desa Singosari, Boyolali). Simposium Nasional Teknologi Terapan (SNTT). $4: 1-10$.

Offayana, G. M., I. W. Widyantara dan I. G. A. A. L. Anggreni. 2016. Analisis risiko produksi stroberi pada UD Mandiri di Desa Pancasari Kecamatan Sukasada Kabupaten Buleleng. E-J. Agribisnis dan Agrowisata. 5 (1) : $1-10$.

Punjawan, I. N. dan L. H. Geraldin. 2009. House of risk : a model for proactive supply chain risk management. Bussines Process Management J. 15 (6): 953 - 967.

Rarasati, C. I., J. Sutrisno dan R. R. A. Qonita. 2015. Analisis Risiko pada Usahatani Kedelai di Kabupaten Grobogan. J. Agrista. 3 (2) : 45 55.

Roessali, W., Masyhuri, S. Nurtini and D. H. Darwanto. 2011. Factors influencing farmers' decision to increase beef cattle business scale in Central Java Province. J. Indonesian Tropical Animal Agriculture. 36 (1) : 27 - 35 .

Setiadi, A., S. I. Santoso, M. Mukson, S. Nurfadillah and K. Prayoga. 2020. Utilization pf electronic marketing and economic determinants to improve income of dairy cattle farmer in Boyolali, Central Java -
Indonesia. J. Indonesian Tropical Animal Agriculture. 45 (3) : 243 249.

Shinta, N. D. dan S. N. Wiyono. 2017. Analisis risiko produksi baby buncis pada kelompok tani di Kabupaten Bandung Barat. JISPO. 7 (2) : $121-136$.

Tasripin, D. S., R. F. Christi dan D. D. Biyantoro. 2020. Produksi susu dan lama laktasi sapi perah friesian holstein di PT Ultra Peternakan Bandung Selatan. Jurnal Ilmu Pertanian. 2(1) : $25-29$. http://ejournal.uicmunbar.ac.id/index.php/composite

Thau, T. D. 2004. The factors affecting technical efficiency of household dairy cattle production in two communes of Gialam District, Hanoi. Journal ISSAAS. 10(1) : 86 -90 .

Utami, A. W., L. B. Salman dan A. Firman. 2020. Analisis efisiensi pada usaha sapi perah di Kecamatan Tanjungsari. J. Pemikiran Masyarakat Ilmiah Berwawasan Agribisnis. 6 (1): 254 $-264$.

Wastra, A. R., R. A. P. Sari dan F. A. Hafiza. 2018. Mitigation of milk production risk in cattle farming (case study on animal husbandary Mahesa Perkasa Farm, Depok City, West Java, Indonesia). J. Advances in Intelligent System Research (AISR). $149: 80-83$. 